Aksaray University
Journal of Science and Engineering
e-ISSN: 2587-1277
http://dergipark.gov.tr/asujse
http://asujse.aksaray.edu.tr

Research Article

\title{
A Study On the Zn(II) Separation Efficiency of Chemically Synthesized Hydroxyapatite (HAp) Particles
}

\author{
Ahmet Dizle $^{1}$, Yağmur Uysal ${ }^{2 *}$ \\ ${ }^{1}$ Institute of Science, Kahramanmaraş Sütçü Imam University, Avşar Kampüsü, 46000, Kahramanmaraş, Turkey \\ ${ }^{2}$ Department of Environmental Engineering, Faculty of Engineering, Mersin University, Mersin 31343, Turkey

\begin{tabular}{|c|c|}
\hline -Received Date: Apr 2, 2021 & $\cdot \operatorname{Rev}$ \\
\hline
\end{tabular}

\begin{abstract}
In this study, hydroxyapatite particles (HAp) were chemically synthesized by using coprecipitation method to determine their capabilities on the sorption of $\mathrm{Zn}(\mathrm{II})$ ions from aqueous solutions. HAp particles were chosen because of their low cost for production, high stability, easy to use, and effective sorption power. In order to determine the operation conditions of the adsorption system to be installed when this adsorbent is desired to be used in field applications, parameters such as system $\mathrm{pH}$, initial $\mathrm{Zn}$ (II) concentration and adsorbent concentrations have been optimized. Properties and functional structure of the adsorbent materials were characterized by using SEM, FTIR, and EDX analyzes. The kinetic behavior of Zn(II) adsorption with HAp was consistent with the pseudo second order kinetic model. Additionally, the equilibrium states of the adsorption processes were studied by using Langmuir, Freundlich, Temkin, Scatchard and Dubinin-Radushkevich (D-R) isotherm models. The maximum sorption capacity HAp was obtained as $500 \mathrm{mg} / \mathrm{g}$, and best removal value of $91 \%$ were determined at $\mathrm{pH}$ of 6.0 , optimum adsorbent concentration of $3.75 \mathrm{~g} / \mathrm{L}$, in $25 \mathrm{mg} / \mathrm{L} \mathrm{Zn(II)}$ concentration and optimum mixing time of $45 \mathrm{~min}$. This study showed that the HAp can be considered an effective adsorbent on the $\mathrm{Zn}(\mathrm{II})$ removal from wastewater.
\end{abstract}

\section{Keywords}

Adsorption, Hydroxyapatite, HAp, Removal, Zn(II)

*Corresponding Author: Yagmur Uysal, yuysal@mersin.edu.tr, (10000-0002-7217-8217 


\section{INTRODUCTION}

Heavy metals such as $\mathrm{Zn}(\mathrm{II}), \mathrm{Cd}(\mathrm{II}), \mathrm{Cr}(\mathrm{VI})$, and $\mathrm{Pb}(\mathrm{II})$ etc. have toxic properties, so they are harmful to all livings. Many industrial wastewater contains these ions in different concentrations, so they must be removed from the discharges before reach to the receiving environments. High concentrations of $\mathrm{Zn}(\mathrm{II})$ have been observed in wastewaters from pharmaceutical, galvanizing, paint, pigment, insecticide, cosmetic industries, and leachate of landfills $[1,2]$. Many treatment techniques have been used to remove these trace ions from water and wastewater such as adsorption, chemical precipitation, filtration, complexing, and electrochemical treatment. The most important parameters before choosing the most appropriate treatment methods for an application should be economy and sustainability of the used technique when considering large volumes of wastewaters. Adsorption is an effective, speed and economical method wastewater treatment applications when adsorbents used in have high sorption capacities [3]. In recent years, researchers have been moving towards producing and using innovative adsorbents such as hydroxyapatite, polymeric materials and biomass [4, 5]. For example, Çelebi et al. [6] investigated the heavy metal removal efficiency of some brewed tea wastes (Camellia sinensis) from simulated watery solution. They found that optimum $\mathrm{pH}$ as 4.0-5.0 to remove $\mathrm{Pb}, \mathrm{Zn}, \mathrm{Ni}, \mathrm{Cd}$ ions from water by adsorption method. The authors emphasized that when using the brewed tea wastes in the adsorption process, the equilibrium values were reached in a short time (2, 10, 30 and 5 minutes, respectively) in the removal of $\mathrm{Pb}, \mathrm{Zn}, \mathrm{Ni}$ and $\mathrm{Cd}$, and that the tea wastes had the potential to be used in the removal of heavy metals. Using tea wastes, maximum adsorption capacities were obtained for $\mathrm{Pb}, \mathrm{Zn}$, $\mathrm{Ni}$ and $\mathrm{Cd}$ as $1.197,1.457,1.163$ and $2.468 \mathrm{mg} / \mathrm{g}$, respectively.

Similarly, eggshell powder (ESP) has been tried as an inexpensive adsorbent material to remove different heavy metals from water by adsorption method. The highest Cd(II) removal efficiency was found at $\mathrm{pH} 5.0$, an initial ESP dosage of $3.5 \mathrm{~g}$, temperature at $20^{\circ} \mathrm{C}$, agitation speed at $250 \mathrm{rpm}$ and contact time of 60 minutes. The maximum removal efficiency of ESP for Cd(II) ions was obtained between $65 \%$ and $96 \%$ under optimum conditions (pH 5.0, $3.5 \mathrm{~g}$ ESP and 60 $\mathrm{min}$ ) and the maximum adsorption capacity was $2.221 \mathrm{mg} / \mathrm{g}$ [7].

Recently, nanometer-sized adsorbents such as iron oxide-based materials with superparamagnetic characteristics have been commonly used as adsorbents due to their low toxicity, ease of synthesis and economic compared to commonly used adsorbents [8,9]. Nanoadsorbents can be used in the environmental purification techniques because of their high sorption capacity within a short time $[10,11]$. 
The apatites are natural calcium phosphate mineral which can be extracted from soil, used in agriculture, in bone tissue and in nature. In most of the studies conducted in recent years, hydroxyapatite (HAp) $\left(\mathrm{Ca}_{5}\left(\mathrm{PO}_{4}\right)_{3}(\mathrm{OH})\right)$, which has porous structure and is presented in the structure of natural bones, teeth, eggshells and also shells of some animals, is used as natural adsorbent for water purification. In addition, its production is easier and uncomplicated than other adsorbents for practical applications than other adsorption materials such as biochar, clays [12], and nanotubes and zeolites [13, 14]. There are many studies using HAp as a natural adsorbent material to remove several metal ions. For example, adsorption potential of HAp for $\mathrm{Pb}(\mathrm{II}), \mathrm{Cd}(\mathrm{II}), \mathrm{Zn}(\mathrm{II}), \mathrm{Sr}(\mathrm{II})$ ions were studied and quite high removal efficiencies were obtained in literature [15-17]. In addition, it was also reported that phosphate content in the HAp provided immobilization of metal ions, and a dissolution-precipitation mechanism of metal phosphates contributed the metal removal [18].

In this study, $\mathrm{Zn}(\mathrm{II})$ adsorption capacity of hydroxyapatite particles prepared by coprecipitation method was investigated. The experimental factors affecting the process such as $\mathrm{pH}$, reaction time, and concentration of $\mathrm{Zn}(\mathrm{II})$ were determined. In order to find rate of the adsorption of $\mathrm{Zn}(\mathrm{II})$ ions, kinetic studies were also made, and kinetic and isotherm models that best describe the research results were explained.

\section{MATERIALS AND METHODS}

\subsection{Chemicals}

All chemicals used in this research such as $\mathrm{Ca}\left(\mathrm{NO}_{3}\right)_{2} \cdot 4 \mathrm{H}_{2} \mathrm{O},\left(\mathrm{NH}_{4}\right)_{2} \mathrm{HPO}_{4}, \mathrm{NH}_{4} \mathrm{OH}(25 \%)$ were analytical grade (purchased from Merck). $\mathrm{Zn}(\mathrm{II})$ stock solutions were prepared from $\mathrm{ZnCl}_{2}$. $\mathrm{pH}$ adjustments were made by using $0.1 \mathrm{M} \mathrm{HCI} \mathrm{(37 \% )} \mathrm{and} 0.1 \mathrm{M} \mathrm{NaOH}$ solutions (Merck).

\subsection{Synthesis of HAp Particles}

HAps were prepared with according to Wang et al. [19] from $\mathrm{Ca}\left(\mathrm{NO}_{3}\right)_{2} .4 \mathrm{H}_{2} \mathrm{O}(0.4 \mathrm{M})$ and $\left(\mathrm{NH}_{4}\right)_{2} \mathrm{HPO}_{4}(0.16 \mathrm{M})$. First, a homogeneous mixture of $\left(\mathrm{NH}_{4}\right)_{2} \mathrm{HPO}_{4}(0.16 \mathrm{M})$ and $\mathrm{Ca}\left(\mathrm{NO}_{3}\right)_{2} .4 \mathrm{H}_{2} \mathrm{O}(0.4 \mathrm{M})$ was prepared. $\left(\mathrm{NH}_{4}\right)_{2} \mathrm{HPO}_{4}$ solution was mixed up to $60^{\circ} \mathrm{C}$ by using magnetic stirrer, and added to the $\mathrm{Ca}\left(\mathrm{NO}_{3}\right)_{2} \cdot 4 \mathrm{H}_{2} \mathrm{O}$ solution at $60^{\circ} \mathrm{C}$. White color was observed during this addition. $5 \mathrm{M} \mathrm{NH}_{4} \mathrm{OH}$ solution was added until the $\mathrm{pH}$ of the mixture was 10. It was then stirred at $60^{\circ} \mathrm{C}$ for 3 hours. The mixture was left for $24 \mathrm{~h}$ at room temperature. The white precipitate formed was washed with ultrapure water until it reached to neutral $\mathrm{pH}$. Then it was separated from the liquid phase with the help of centrifuge, and dried at $80^{\circ} \mathrm{C}$. As a result of these experimental sequences, adsorbent material was obtained and the calculated reaction 
efficiency was found to be $80 \%$. The precipitates of HAp were isolated by centrifugation and washed with pure water to reach neutral $\mathrm{pH}$. Then precipitates were dried at $80{ }^{\circ} \mathrm{C}$ overnight to obtain the HAp adsorbent.

\subsection{Adsorbent Characterization}

Particle sizes and their morphology of synthesized HAp particles were characterized by a Scanning Electron Microscope (SEM- ZEISS/EVO LS10 Model). The characterization of the adsorbents was analyzed by FTIR (Fourier Transform Infrared Spectrophotometer-Perkin Elmer Spectrum 400 Model), and Energy Dispersive X-Ray Analysis (EDX-ZEISS/EVO LS10 Model) for elemental analysis. The $\mathrm{pH}$ measurements were made by $\mathrm{pH}$-meter (Hanna HI 2211 pH/ORP). ICP-OES (Optima 2100-Perkin Elmer) was used to determine Zn(II) concentrations in water.

\subsection{Experiments}

The $\mathrm{pH}$ effect on $\mathrm{Zn}$ (II) removal was studied by mixing $6.25 \mathrm{~g} / \mathrm{L}$ HAp with $25 \mathrm{mg} / \mathrm{L} \mathrm{Zn}$ (II) containing solutions. The $\mathrm{pH}$ was adjusted to $\mathrm{pH}$ 2.0-9.0 range. Because of the metal hydroxide precipitation occurred at $\mathrm{pH}>8.5$, the maximum $\mathrm{pH}$ value was chosen as $\mathrm{pH} 9.0$. Experiments were conducted at different HAp dosages of 1.25-12.5 g/L with constant $\mathrm{pH}$ (optimum) and 25 $\mathrm{mg} / \mathrm{L} \mathrm{Zn}(\mathrm{II})$ concentration to find optimum adsorbent concentration. Similarly, different $\mathrm{Zn}(\mathrm{II})$ concentrations of 10-100 $\mathrm{mg} / \mathrm{L}$, and different reaction times of 5-180 min experiments were conducted at to find optimal conditions. According to the water pollution control regulation, the receiving environment discharge standard for industries such as metal, mining, chemical, textile and petroleum industry that discharges wastewater containing zinc ions varies from 3$12 \mathrm{mg} / \mathrm{L}$. For this reason, $10-100 \mathrm{mg} / \mathrm{L}$ was chosen for the initial concentration range for zinc ions in our study and to include the high range. The kinetic behavior of $\mathrm{Zn}(\mathrm{II})$ adsorption on MHAp was studied by measuring its residual concentrations with time intervals. The $\mathrm{Zn}(\mathrm{II})$ uptake capacity, q (mg/g) was examined based on the Eq. 1;

$q=\frac{C_{0}-C_{e}}{M}$

$\mathrm{C}_{0}$ and $\mathrm{C}_{\mathrm{e}} ; \mathrm{Zn}(\mathrm{II})$ concentrations at the beginning of the experiments and at equilibrium after adsorption (mg/L), V; solution volume (L), and M; mass of the HAp (g/L).

\subsection{Kinetic Experiments}

Adsorption kinetics refer to the time dependence of the adsorption process. The most commonly used equations developed for the purpose of explaining the adsorption kinetics are first degree, pseudo second degree and intraparticle diffusion. The first-order kinetic model introduced by 
Lagergren has been applied for the initial stages in which the adsorption process has not yet reached its equilibrium. This equation is as follows (Eq 2) [20].

$\frac{d q}{d t}=k_{1}\left(q_{e}-q_{t}\right)$

After the integration, equation is converted to formula below, Eq. 3.

$\log \left(q_{e}-q_{t}\right)=\log \left(q_{e}\right)-\frac{k_{1}}{2.303} t$

In this equation, $\mathrm{q}_{\mathrm{e}}$ and $\mathrm{q}_{\mathrm{t}}$ show the adsorbate amount on the adsorbent at equilibrium and at any time of $\mathrm{t} . \mathrm{k}_{1}$ is rate constant $(1 / \mathrm{min})$. The equation of the second order kinetic model, which is in harmony with the speed control mechanism throughout the adsorption period, is as follows (Eq. 4) [21].

$\frac{t}{q_{t}}=\frac{1}{k_{2} q_{e}^{2}}+\frac{t}{q_{e}}$

$\mathrm{k}_{2}$ shows the rate constant (g/mg.min), and it is calculated from the slope and intercept values. This model provides to design and find size of the adsorption reactor for pilot scale and real applications.

Intraparticle diffusion model (Weber-Morris) was developed to define an inexplicable adsorption model with first and second degree models [22] (Eq. 5);

$q_{e}=k_{p} t^{0.5}$

where; $\mathrm{k}_{\mathrm{p}}$ is intra-particle diffusion model rate constant for $(\mathrm{mg} / \mathrm{g} 1 / 2) ; \mathrm{t}^{0.5}$ : half time (min); $\mathrm{C}$ : equilibrium ratio constant for intra-particle diffusion model.

\subsection{Adsorption Isotherms}

The equilibrium data of adsorption processes were analyzed using the Langmuir (Eq. 6), Freundlich (Eq. 7), Dubinin Radushkevich (D-R) (Eqs. 9-10), Tempkin (Eqs. 11-12), and Scatchard (Eq. 13) adsorption isotherm models:

$\frac{1}{q_{e}}=\frac{1}{b q_{m} C_{e}}+\frac{1}{q_{m}}$

$\operatorname{Inq}_{e}=\operatorname{In} K_{f}+\frac{1}{n \operatorname{InC} C_{e}}$

where, $\mathrm{q}_{\mathrm{e}}(\mathrm{mg} / \mathrm{g})$ is HAp capacity for $\mathrm{Zn}(\mathrm{II})$ adsorption, $\mathrm{C}_{\mathrm{e}}$ is $\mathrm{Zn}(\mathrm{II})$ concentration in equilibrium (mg/L), $\mathrm{q}_{\mathrm{m}}$ is maximum capacity of HAp for $\mathrm{Zn}(\mathrm{II})$ adsorption (mg/g), $\mathrm{K}_{\mathrm{F}}$ and $\mathrm{K}_{\mathrm{L}}$ are the coefficients of Freundlich and Langmuir models, and $n$ is the exponent of Freundlich model.

Freundlich and Langmuir isotherms are commonly used isotherms to explain the relationship between adsorbent and adsorbate in the removal of various contaminants from water. The 
Langmuir isotherm model is used to express the monolayer surface adsorption of contaminants to a limited number of binding points on the adsorbent surface. Freundlich isotherm states that the bonding is not in the form of a single layer on the surface, but bonding occurs by overlapping more than one layer. The interaction of metal ions and biosorbents was further examined by separation factor $\left(R_{L}\right)$. $R_{L}$ equals to a dimensionless constant separation factor, as an equilibrium parameter derived from the Langmuir model. The $\mathrm{R}_{\mathrm{L}}$ was described by Hall et al. [23] and was shown in Eq. (8). $R_{L}$ values imply that the isotherm is favorable $\left(0<R_{L}<1\right)$, unfavorable $\left(R_{L}>1\right)$, linear $(R=1)$, or irreversible $(R=0)$.

$R_{L}=\frac{1}{1+b C_{0}}$

Dubinin Radushkevich (D-R) isotherm gives information about the porosity of the system. The basis of the isotherm equation is based on the micropore volume distribution [24]. As the adsorption energy decreases, the capacity of the adsorbate to fill the pores on the adsorbent is increased.

$\varepsilon=\operatorname{RTIn}\left(1+\frac{1}{C_{e}}\right)$

$\operatorname{Inq} q_{e}=\operatorname{In} Q_{s}-B \varepsilon^{2}$

Where; Qs: Maximum adsorption capacity of HAp for $\mathrm{Zn}(\mathrm{II})$ adsorption (mg/g); B: D-R isotherm constant; $\varepsilon$ : Polanyi adsorption potential $(\mathrm{kJ} / \mathrm{mol}) ; \mathrm{R}$ : Universal gas constant $(8.3144$ $\left.\mathrm{J} /{ }^{\circ} \mathrm{K} . \mathrm{mol}\right) ; \mathrm{T}$ : Temperature $\left({ }^{\circ} \mathrm{K}\right)$

Interactions between the adsorbed substances are taken into account in the Tempkin isotherm. This isotherm was developed according to the adsorption enthalpy of all molecules in solution, and assumes that heat of adsorption of all the molecules in the layer decreases linearly with coverage due to adsorbent-adsorbate interactions $[25,26]$.

$q_{e}=B \operatorname{In} A_{T}+B \operatorname{In} C_{e}$

$B=\frac{R T}{b_{t}}$

$\mathrm{b}_{\mathrm{t}}$ : Temkin isotherm constant $(\mathrm{J} / \mathrm{mol}) ; \mathrm{A}_{\mathrm{T}}$ : Equilibrium binding constant $(\mathrm{L} / \mathrm{g})$; T: Temperature $\left({ }^{\circ} \mathrm{K}\right)$

Scatchard isotherm can give more reliable results than Langmuir and Freundlich isotherm equations when it is used for the characterization of various materials, and characteristics of the adsorbate material. In other words, it is possible to comment on the suitability of the Langmuir and Freundlich models from the Scatchard curve derived for an adsorption process.

$\frac{q_{e}}{C_{e}}=Q_{s} K_{s}-q_{e} K_{s}$

where; $\mathrm{Q}_{\mathrm{s}}$ : Maximum adsorption capacity of HAp for $\mathrm{Zn}(\mathrm{II})$ adsorption (mg/g), and $\mathrm{K}_{\mathrm{s}}$ :

Binding constant 


\section{RESULTS AND DISCUSSION}

\subsection{Characterizations Of The Adsorbents}

The structural properties of the adsorbent used in the adsorption process are important factors affecting the adsorption rate and efficiency. The surface area, particle size and structure of the adsorbent are factors affecting the adsorption efficiency. Increasing of surface area and decreasing of particle size affect all adsorption processes positively. In the present study, FTIR analyzes were made to determine the chemical characterization of adsorbent before and after the adsorption as below (Fig. 1).

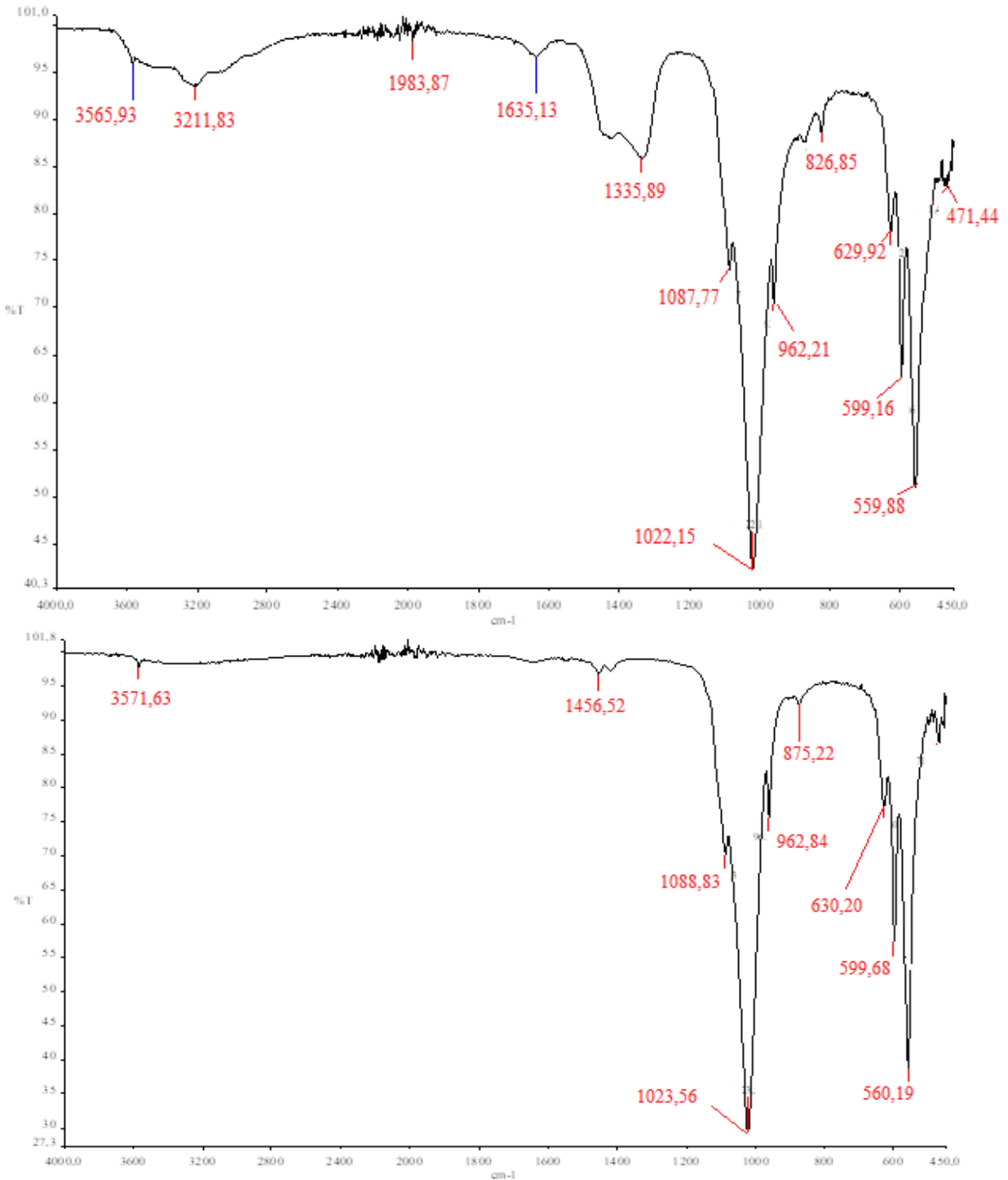

Figure 1. FTIR analyzes before $(a)$ and after $(b)$ the adsorption process of the HAp

In the FTIR spectrum, the signaling of the oxygen-hydrogen $(\mathrm{O}-\mathrm{H})$ bonds was observed in the $3565 \mathrm{~cm}^{-1}$ and $3571 \mathrm{~cm}^{-1}$ regions. The peaks at 1635 , and $1022-1023 \mathrm{~cm}^{-1}$ correspond the $\mathrm{C}=\mathrm{C}$ and $\mathrm{C}=\mathrm{O}$ stretching [27]. The peaks in the $599 \mathrm{~cm}^{-1}$ and in the $560 \mathrm{~cm}^{-1}$ regions are considered to the low phosphate stretch zone (tensile vibrations of $\mathrm{PO}_{4}{ }^{3-}$ in the HAp) [28]. The peaks in 
the area of $1335 \sim 1456 \mathrm{~cm}^{-1}$ are considered to belong to the high phosphate stretch region. Adsorption occurs as a result of displacement of $\mathrm{Ca}^{+2}$ and $\mathrm{Zn}^{+2}$ ions in 1456 and $1335 \mathrm{~cm}^{-1}$ band [29]. The FTIR spectrum confirmed that the hydroxyapatite contains oxygenated functional groups. Since all these groups are available adsorption zones, they have a great role in heavy metal removal [30]. The results also showed that there were changes in the location and intensity of peaks after the adsorption. It was interpreted that peaks at $3565-3211 \mathrm{~cm}^{-1}, 1635$ $1335 \mathrm{~cm}^{-1}$ regions were relatively lost after adsorption, and zinc could be bounded to the bonds in these regions. Therefore, it is concluded that the adsorption of zinc ions to the surface of the adsorbents is chemical.
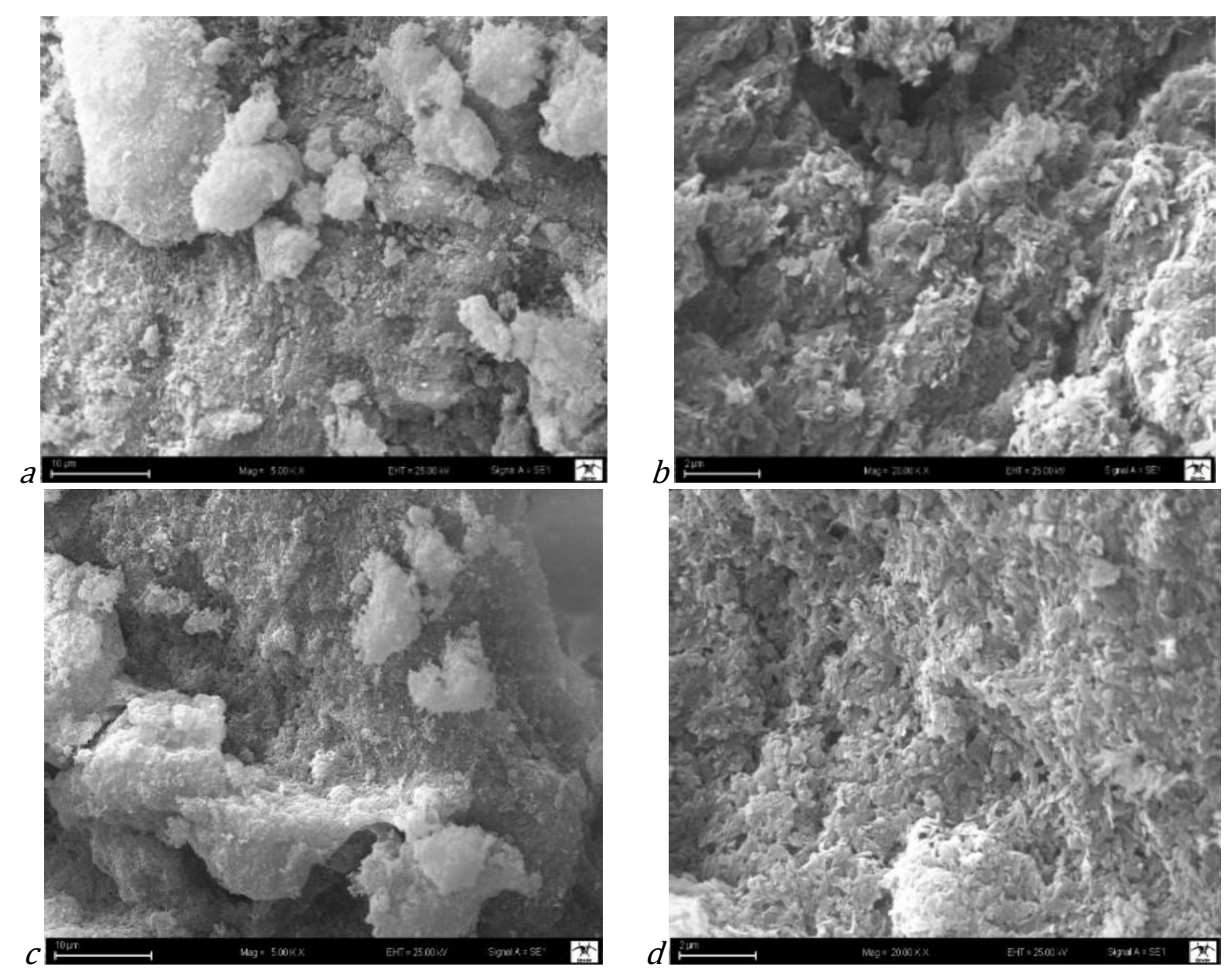

Figure 2. SEM surface analyses of hydroxyapatite particles before $(a, b)$ and after $(c, d)$ the adsorption process

SEM surface analyses of the adsorbent were investigated before and after the treatment process, and the following images were obtained (Fig. 2). The results showed that the adsorbent is generally composed of fine and spherical particles and has an irregular and porous structure. Therefore, these pores on the surface of the adsorbent can explain their effectiveness in the removing of metal ions. When the post-adsorption results were examined, it was shown that this porous and hollow structure is less than before and the adsorption is successful. After the 
adsorption, it was determined that the pores and cavities on the adsorbent surfaces were closed and the pores were closer to each other.
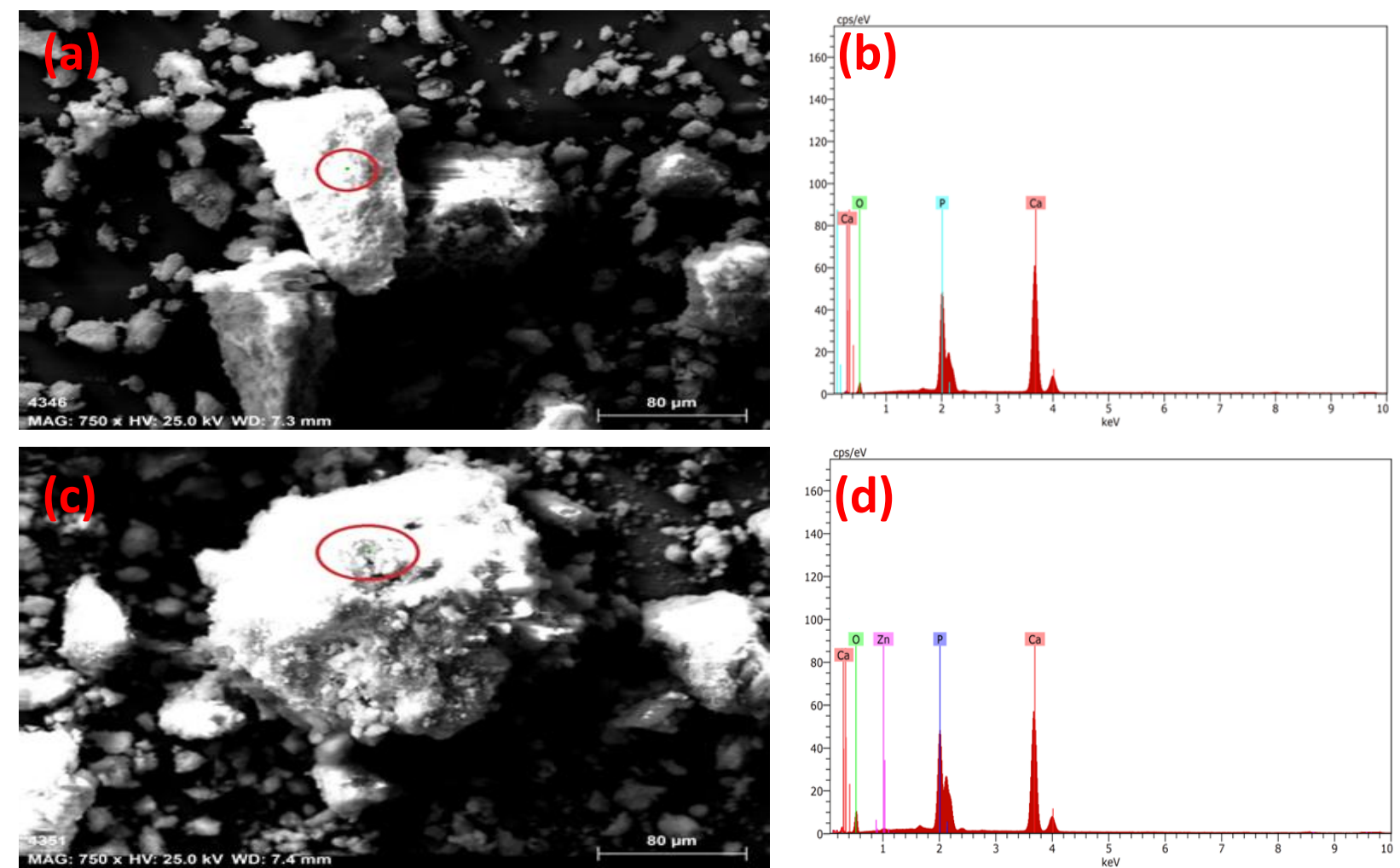

Figure 3. EDX analysis of HAp particles before $(a, b)$ and after $(c, d)$ the adsorption

The data obtained from the EDX elemental analyses of the adsorbent are shown in Fig. 3. In the EDX analyses carried out at one point of the adsorbent, the presence of elements in the structure of the adsorbent appears before the adsorption. The presence of zinc in addition to the elements in the adsorbent structure in the post-adsorption EDX analysis showed that $\mathrm{Zn}$ (II) ions were successfully adsorbed on the HAp surface.

Elemental analysis of pure hydroxyapatite showed that it contains $56.02 \%$ Calcium (Ca), 22.28\% Oxygen (O) and 21.70\% Phosphorus (P) in its mass. After the adsorption process, its EDX analysis showed that it contains $42.14 \% \mathrm{Ca}, 24.84 \% \mathrm{O}, 21.72 \% \mathrm{P}$, and $11.28 \% \mathrm{Zn}$ (II) in its mass. The presence of the $\mathrm{Zn}$ (II) ions indicates the $\mathrm{Zn}(\mathrm{II})$ adsorption of hydroxyapatite. Moreover, the reason for the decrease in calcium concentration after contact can be explained by the replacement of $\mathrm{Zn}$ (II) ions with $\mathrm{Ca}$ (II) ions on the surface.

\subsection{Experiments}

\subsubsection{The change of $\mathrm{Zn}(\mathrm{II})$ adsorption by HAp with $\mathrm{pH}$}

The $\mathrm{pH}$ effects the solubility/precipitation conditions, mobility of metal ions, and also surface properties of the adsorbents. In addition, solution $\mathrm{pH}$ is important as it affects the surface charge of the adsobent and the availability of metal ions in aqueous solution as free metal ions [31]. 
Thus, solution $\mathrm{pH}$ affects the adsorption of metal ions on adsorbent surface directly. In order to investigate the effect of different initial $\mathrm{pH}$ on adsorption process, HAp particles $(6.25 \mathrm{~g} / \mathrm{L})$ were added to the flasks containing 10 and $25 \mathrm{mg} / \mathrm{L}$ of $\mathrm{Zn}(\mathrm{II})$ solutions at different initial $\mathrm{pH}$ (2.0-9.0), and batch adsorption tests were made at room temperature $\left(23{ }^{\circ} \mathrm{C}\right)$ for 60 minutes (Fig. 4).

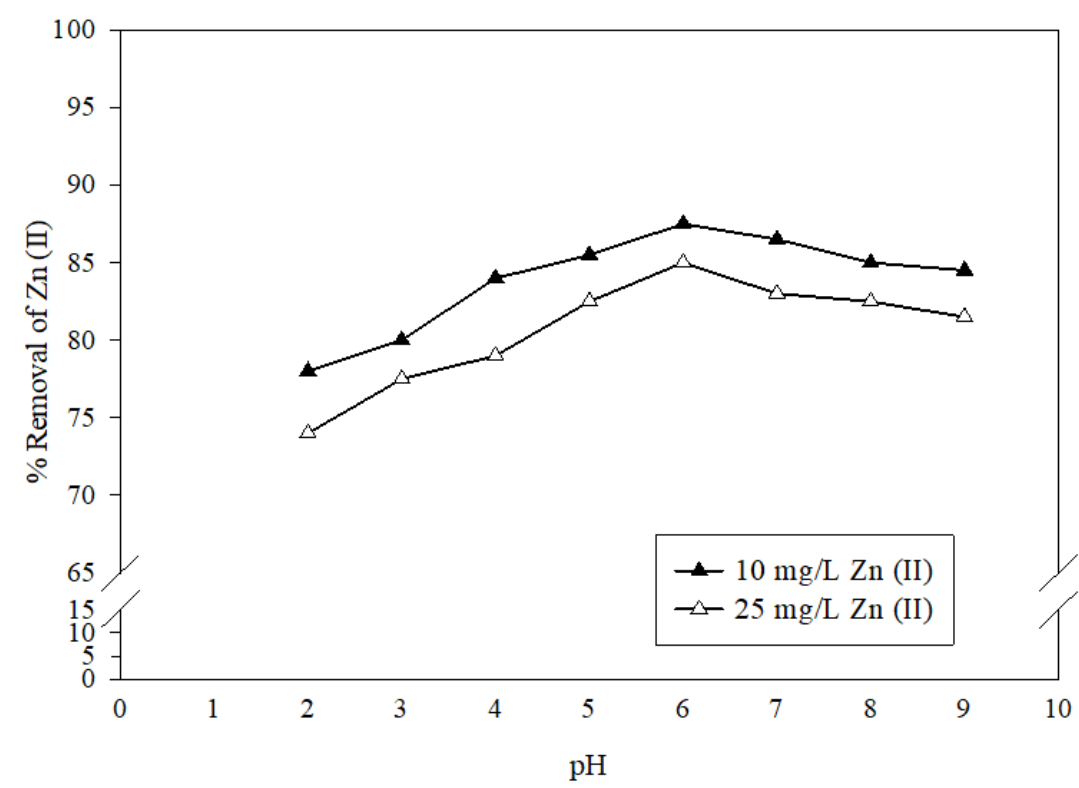

Figure 4. The change of $\mathrm{Zn}(\mathrm{II})$ removal by $\mathrm{pH}$ (HAp: $6.25 \mathrm{~g} / \mathrm{L}$, t: $60 \mathrm{~min}$ )

As seen in the Fig. 4, solution $\mathrm{pH}$ has a strong effect on the $\mathrm{Zn}(\mathrm{II})$ adsorption by HAp and the percentage of adsorbed $\mathrm{Zn}$ (II) increased with the increase of the solution $\mathrm{pH}$ up to 6.0. Removal efficiencies for HAp at $\mathrm{pH} 2.0-9.0$ range were found in the range of 78.0-87.5\% and 74.0-85.0\% for 10 and $25 \mathrm{mgZn}(\mathrm{II}) / \mathrm{L}$, respectively. An increase in the adsorption efficiency was observed at $\mathrm{pH}$ values of 2.0-6.0. In order to the decrease in the density of the positive charges on the solid surfaces with the increase of $\mathrm{pH}$, also decrease of competition between the $\mathrm{Zn}$ (II) and $\mathrm{H}^{+}$ ions for active adsorbent sites, the removal efficiency of $\mathrm{Zn}(\mathrm{II})$ decreased with higher $\mathrm{pH}$ values as a result of the decrease of electrostatic forces and precipitation of metal ions with the hydroxide in the solution. Thus, $\mathrm{pH} 6.0$ was selected as the optimal $\mathrm{pH}$ value because of closing to neutral $\mathrm{pH}$, avoiding to surface protonation at lower $\mathrm{pHs}$, and to precipitation of $\mathrm{Zn}$ (II) ions at high pHs. Thus, $\mathrm{pH}$ for $\mathrm{Zn}(\mathrm{II})$ adsorption was fixed at 6.0 in the next adsorption experiments. Thanh et al. [32] used the magnetite-hydroxyapatite nanocomposite for the removal of $\mathrm{Cu}$ (II) and nickel $\mathrm{Ni}$ (II) ions from the solutions. In order to determine the effect of $\mathrm{pH}$ on the adsorption process, they tried different $\mathrm{pH}$ ranges of 3.0-5.0 and 3.0-7.0, and they found optimum pH values for $\mathrm{Cu}$ (II) and Ni (II) as 5.0 and 7.0, respectively. Similarly, Nahid et al. [33] used magnetite amino nanoparticles as adsorbent for $\mathrm{Zn}(\mathrm{II})$ removal. They carried out the experiments at different initial $\mathrm{pH}$ range of 2.0-7.0, initial $\mathrm{Zn}(\mathrm{II})$ concentration of 5-20 mg/L, 
adsorbent dosages of 0.005-0.040 g/25 mL, adsorption time of 5-120 $\mathrm{min}$, and temperature of $308-333{ }^{\circ} \mathrm{K}$ range. They reached the best $\mathrm{Zn}(\mathrm{II})$ removal at $\mathrm{pH}$ range of 6.0-8.0.

These results are similar to those obtained in previous studies on the adsorption behavior of $\mathrm{Zn}$ (II) on various adsorbent materials such as mixed column clays [34]; geopolymeric LinzDonawitz powder [35] and hydrous manganese dioxide [36]. Thanh et al. [32] reported that four mechanisms such as complex formation, ion exchange, dissolution-precipitation and electrostatic interaction on the adsorbent surface are effective on metal retention by magnetite composite and raw hydroxyapatite adsorbents. Other mechanisms such as surface sorption and complexation were suggested by other researches for metal ions at high $\mathrm{pH}$ values (>4.0) [37].

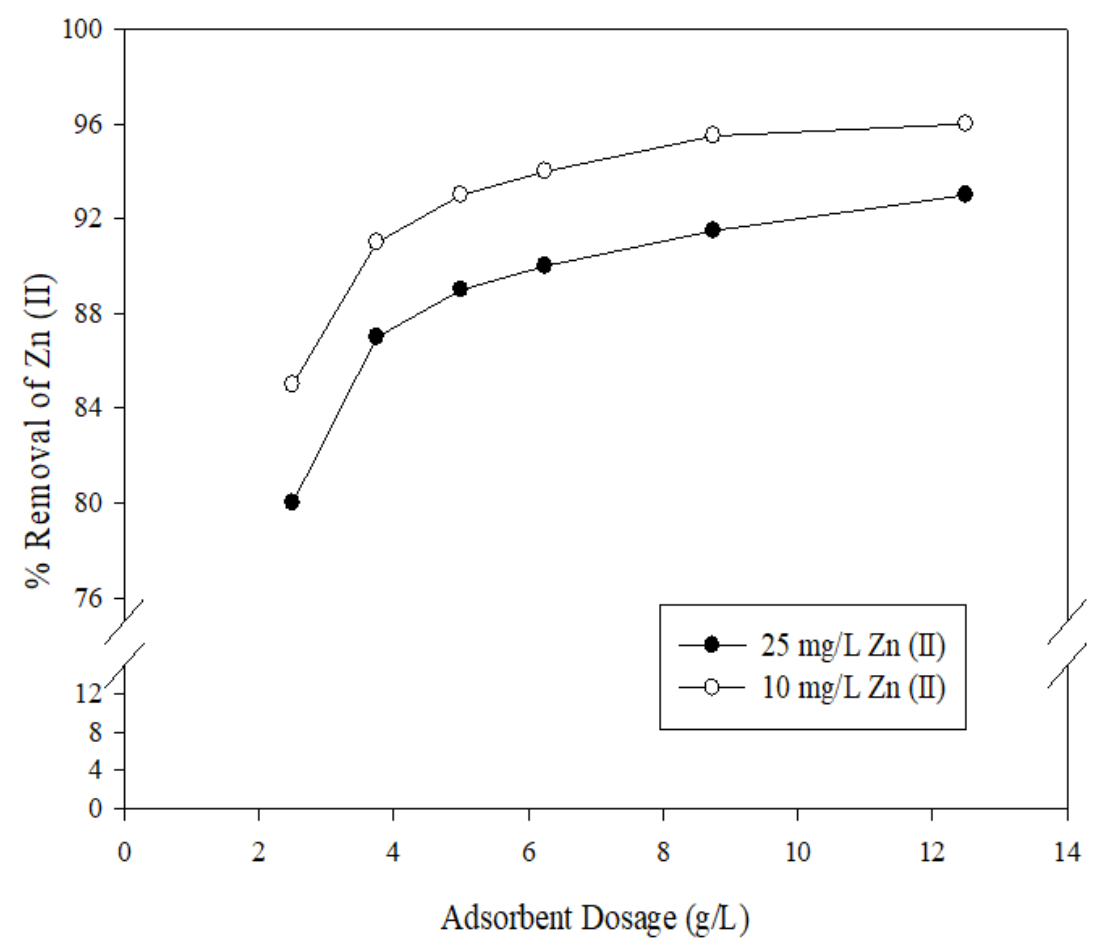

Figure 5. The change of $\mathrm{Zn}(\mathrm{II})$ removal by HAp dosage (HAp: 2.5-12.5 g/L; t: $60 \mathrm{~min}, \mathrm{pH}: 6.0$ )

\subsubsection{The change of $\mathrm{Zn}$ (II) adsorption by HAp with HAp concentration}

In the adsorption process, reaction rate changes with the amount of adsorbate added to the solution. Since the amount of adsorbate per unit volume will vary at different concentrations, adsorbate amount adsorbed by the adsorbent will also change, and affects the adsorption efficiency depending on the adsorbent capability and capacity. Thus, experiments were made at room temperature $\left(22 \pm 1{ }^{\circ} \mathrm{C}\right)$ for $60 \mathrm{~min}$ by using the amount of adsorbents in the range of 1.25-12.5 g/L at pH 6.0 (Fig. 5). As seen in Fig. 5, the increase of adsorbent concentration caused to increase of $\mathrm{Zn}(\mathrm{II})$ removal efficiency for two different $\mathrm{Zn}$ (II) concentrations. Increasing of binding sites for $\mathrm{Zn}$ (II) with the presence of high adsorbent addition lead to 
increase of active sites on their surface, so this caused to increase of $\mathrm{Zn}$ (II) removal efficiencies. The maximum removal efficiency of $96 \%$ was obtained at the maximum HAp concentration of $12.5 \mathrm{~g} / \mathrm{L}$ while, this value was found as $91 \%$ for $3.75 \mathrm{~g} / \mathrm{L}$ adsorbent concentration. The active surface area and the number of pores on the adsorbent surface increase with increasing of adsorbent concentration, so much more $\mathrm{Zn}$ (II) ions can be further adsorbed on them. In the results shown in Fig 5, the peak in the removal rate was observed at $3.75 \mathrm{~g} / \mathrm{L}$ adsorbent concentration, and there was an only $5 \%$ yield difference between $12.5 \mathrm{~g} / \mathrm{L}$ and $3.75 \mathrm{~g} / \mathrm{L}$ adsorbent concentrations for both $\mathrm{Zn}$ (II) concentrations. Thus, optimum adsorbent concentration for HAp particles was chosen as $3.75 \mathrm{~g} / \mathrm{L}$ to avoid the use of much amount adsorbent considering of economic factors.

Harja and Ciobanu [38] used HAp as adsorbent material to remove oxytetracycline (OTC) from wastewater, and found that OTC removal showed an increase with increasing of adsorbent concentration with surface complexation mechanism. They pointed out that adsorption success of adsorbents increases by increasing of their surface area and related active sites. Periyasamy et al. [39] used hydroxyapatite alginate beads (1-4 g/L) to remove $\mathrm{Cr}(\mathrm{VI})$ (100-200 mg/L) from water, and they determined optimum adsorbent concentration as $4 \mathrm{~g} / \mathrm{L}$ for these experimental conditions.

Wang et al. [19] also worked on hydroxyapatite-biochar nanocomposite (HAp-BC) to remove metal ions such as lead, zinc and copper, and they reported that when the solution $\mathrm{pH}$ is too acidic ( $\mathrm{pH}<2.5$ ), heavy metal adsorption can be negatively affected by the adsorbent surface being positively charged.

\subsubsection{The change of $\mathrm{Zn}(\mathrm{II})$ adsorption by concentration and time}

Heavy metals are commonly found in industrial wastewater, and different metal ions can be found in these wastewaters in different concentrations depending on the type of water and industry. Therefore, the initial concentration of heavy metal ions to be removed in adsorption studies is a factor affecting the process efficiency. In our study, $\mathrm{Zn}(\mathrm{II})$ concentration effect (10$100 \mathrm{mg} / \mathrm{L}$ ) on adsorption was determined by keeping the other parameters constant ( $\mathrm{pH}: 6.0$, HAp: $\left.3.75 \mathrm{~g} / \mathrm{L}, \mathrm{t}: 60 \mathrm{~min}, \mathrm{~T}: 22 \pm 2^{\circ} \mathrm{C}\right)$.

The adsorbed $\mathrm{Zn}$ (II) concentration decreased with increasing of initial $\mathrm{Zn}$ (II) concentration because of their active sites were constant (Fig. 6). In the lowest $\mathrm{Zn}$ (II) concentration of 10 $\mathrm{mg} / \mathrm{L}$, the removal efficiency of HAp was measured as $88 \%$. However, it was decided to choose optimum initial concentration of $\mathrm{Zn}(\mathrm{II})$ as $25 \mathrm{mg} / \mathrm{L}$ because of reaching to quite high removal efficiency of $85 \%$. 


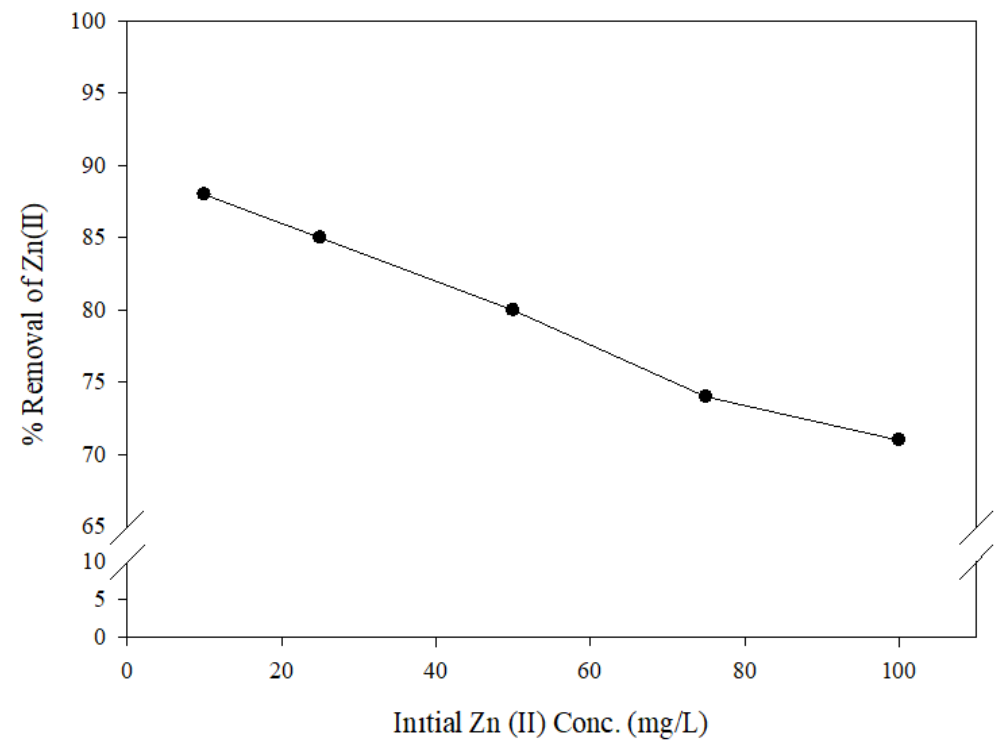

Figure 6. The change of Zn(II) removal by initial Zn(II) concentration (HAp: $3.75 \mathrm{~g} / \mathrm{L}$, t: $60 \mathrm{~min}$, $\mathrm{pH}: 6.0,10-100 \mathrm{mg} / \mathrm{L})$

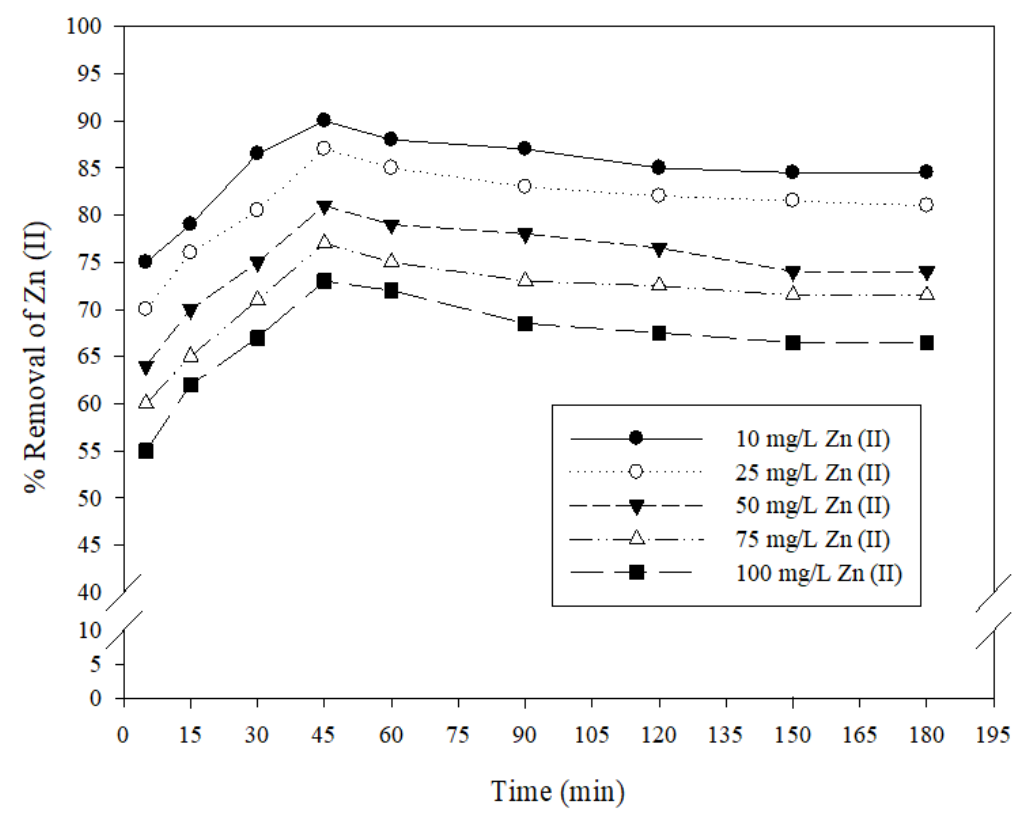

Figure 7. Effect of reaction time on Zn(II) removal (HAp: 3.75 g/L, pH:6.0, 10-100 mgZn(II)/L, t: 5$180 \mathrm{~min})$

In the adsorption process, a certain time is required to adhere the adsorbate to the adsorbent surface. Thus, one of the most important criteria to be determined in the applications of the adsorption is to determine the optimum contact time. Adsorption efficiency will increase with increasing of the contact time up to a certain period, and it will reach to stable value after the reach to equilibrium. In order to determine the effect of contact time on the adsorption, experiments were conducted keeping all other parameters constant (pH 6.0, HAp: $3.75 \mathrm{~g} / \mathrm{L}$, and 10-100 $\mathrm{mgZn}(\mathrm{II}) / \mathrm{L}$ ) for 5-180 min. According to Fig. 7, the removal efficiency reached the maximum in the first 45 min for HAp particles. Although removal efficiencies reduced slightly after reaching to their maximum values, they did not change significantly over time after from 
90 min. $73-90 \%$ of zinc ion adsorption occurred at the first 45 min for HAp particles depending on the initial $\mathrm{Zn}$ (II) concentration levels. This is due to the high level of unsaturated active sites of adsorbents at the start of contact time. In the experiments, in order to determine whether the adsorbent added to the solutions causes changes in the $\mathrm{pH}$ of the water and the effect of these $\mathrm{pH}$ changes on heavy metal removal, the $\mathrm{pH}$ measurements of all the initial $\mathrm{Zn}$ (II) concentrations in the contact time experiment were made and shown in Fig. 8.

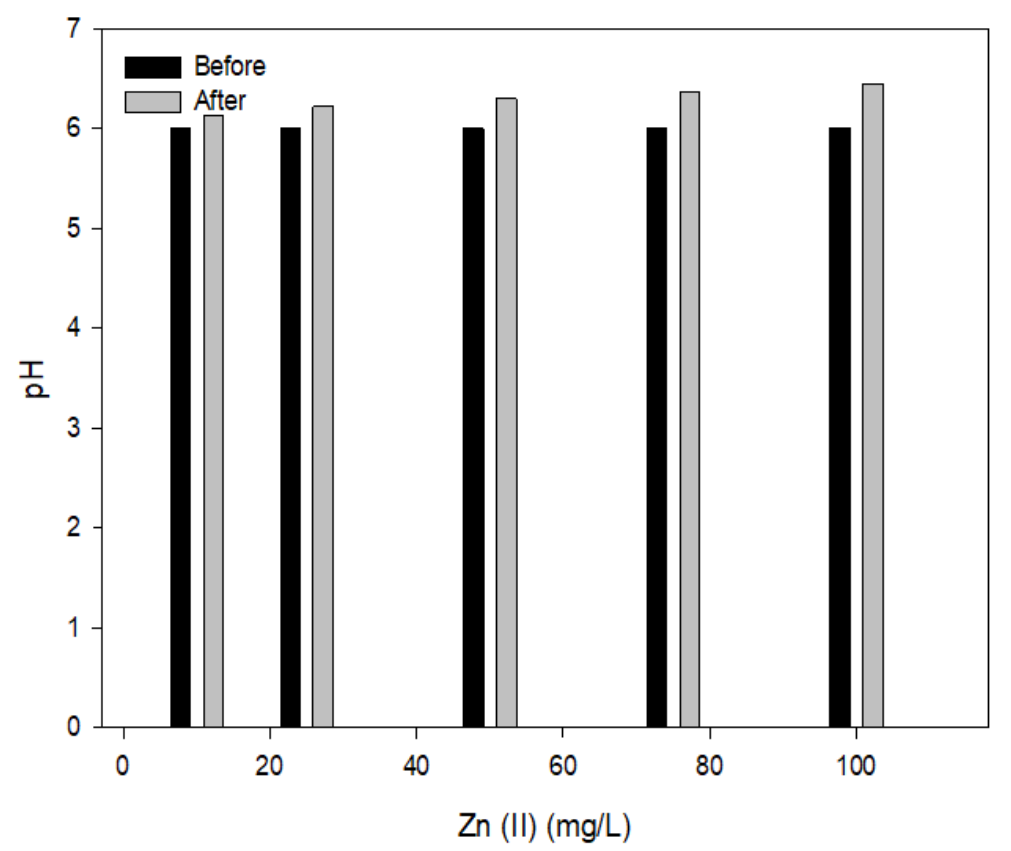

Figure 8. Solution $\mathrm{pHs}$ before and after adsorption according to the initial $\mathrm{Zn}$ (II) concentrations

\subsection{Adsorption Kinetics}

Kinetic experiments are performed to identify and understand the functions that control the adsorption mechanisms such as chemical and/or physical reaction and diffusion. With this aim, time-adsorption capacity results were applied to different kinetic models to find kinetic behavior of $\mathrm{Zn}(\mathrm{II})$ adsorption (Fig. 9), and adsorbent/adsorbate relationships were determined between $\mathrm{Zn}(\mathrm{II})$ and HAp particles (Table 1). The first degree equation was not well suited for describing the kinetic behavior of the $\mathrm{Zn}(\mathrm{II})$ adsorption. However, the pseudo-second degree equation with $\mathrm{R}^{2}$ value of 0.9992 for HAp was found to be best kinetic equation describing $\mathrm{Zn}(\mathrm{II})$ adsorption kinetic on hydroxyapatite powders followed by the diffusion-controlled process which is the intraparticle (pore) diffusion model ( $\left.\mathrm{R}^{2}-\mathrm{HAp}: 0.9643\right)$. The results showed that not only the surface adhesion or surface chemistry is effective on the adsorption rate but also closely related to the pore structure of the hydroxyapatite at the micro or macro level. The results also showed that in the adsorption process, firstly, $\mathrm{Zn}$ (II) ions were rapidly transported to the surface of the adsorbents and then diffused into the particles [39]. 

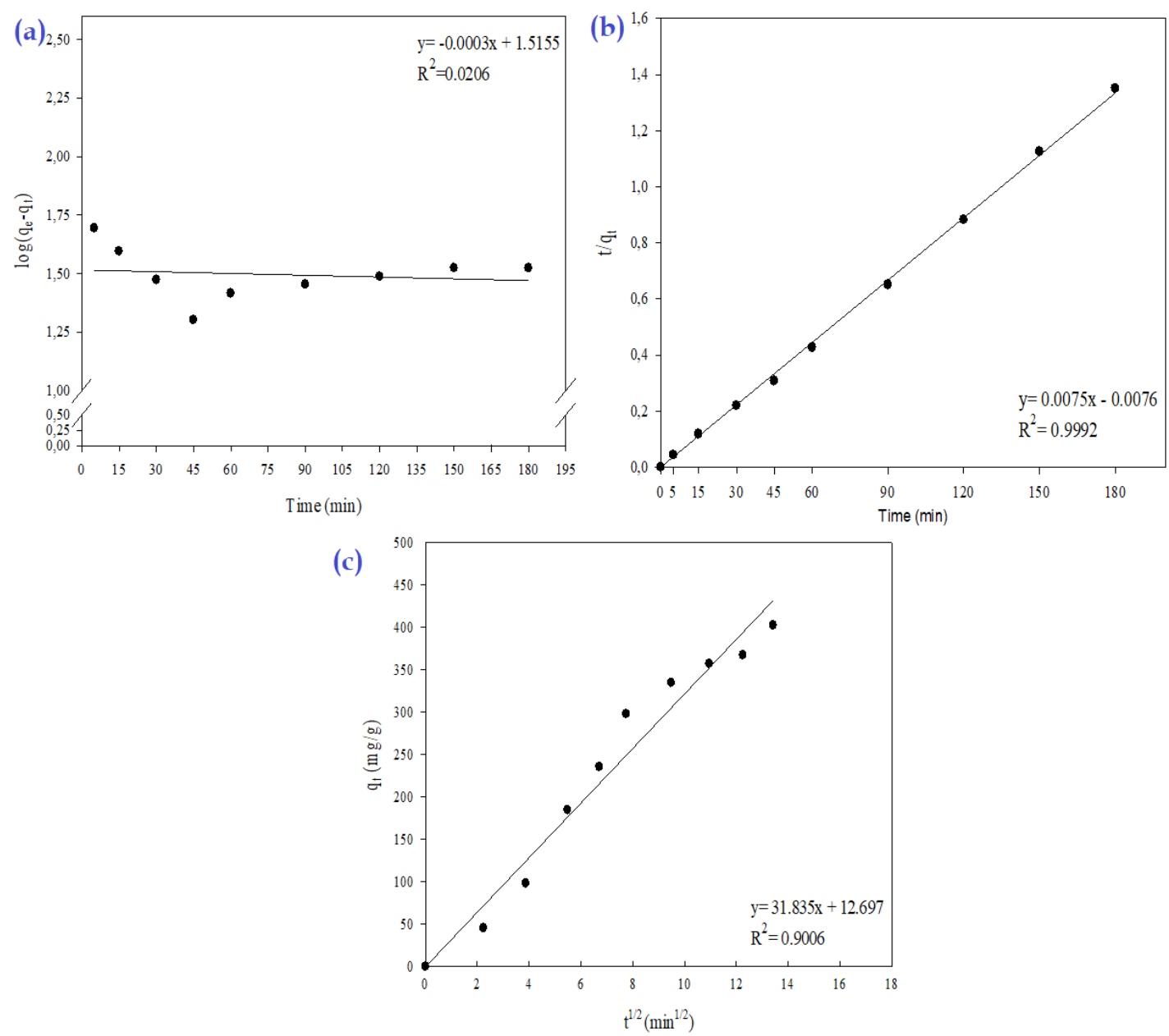

Figure 9. The first degree (a), pseudo-second degree (b) and intraparticle diffusion (c) models for $\mathrm{Zn}(\mathrm{II})$ removal by HAp

Table 1. Kinetic behavior of HAp for Zn(II) removal (pH 6.0, $3.75 \mathrm{~g} / \mathrm{L}, 25 \mathrm{mgZn}(\mathrm{II}) / \mathrm{L}, 22 \pm 2{ }^{\circ} \mathrm{C}$ )

\begin{tabular}{|c|c|c|}
\hline Kinetic models & Parameters & Value \\
\hline \multirow[t]{2}{*}{ First degree kinetic } & $\mathrm{q}_{\mathrm{e}, \mathrm{calc}}(\mathrm{mg} / \mathrm{g})$ & 32.770 \\
\hline & $\mathrm{k}_{1}\left(\min ^{-1}\right)$ & 0.0007 \\
\hline \multirow[t]{4}{*}{$\log \left(\mathrm{q}_{\mathrm{e}}-\mathrm{q}_{\mathrm{t}}\right)=\log \mathrm{q}_{\mathrm{e}}-\left(\mathrm{k}_{1} / 2.303\right) \mathrm{t}$} & $\mathrm{R}^{2}$ & 0.020 \\
\hline & $\mathrm{SS}$ & 0.002 \\
\hline & MS & 0.002 \\
\hline & $\mathrm{P}$ & 0.712 \\
\hline \multirow[t]{2}{*}{ Pseudo-second degree kinetic } & $\mathrm{q}_{\mathrm{e}, \mathrm{calc}}(\mathrm{mg} / \mathrm{g})$ & 133.333 \\
\hline & $\mathrm{k}_{2}$ (g/mg.min) & 0.007 \\
\hline \multirow[t]{4}{*}{$\mathrm{t} / \mathrm{q}_{\mathrm{t}}=\left(1 / \mathrm{k}_{2} \mathrm{q}_{\mathrm{e}}^{2}\right)+\left(1 / \mathrm{q}_{\mathrm{e}}\right) \mathrm{t}$} & $\mathrm{R}^{2}$ & 0.999 \\
\hline & $\mathrm{SS}$ & 4.629 \\
\hline & MS & 0.463 \\
\hline & $\mathrm{P}$ & $<0.0001$ \\
\hline \multirow[t]{6}{*}{ Intraparticle diffusion kinetic } & $\mathrm{C}$ & 12.697 \\
\hline & $\mathrm{k}_{\mathrm{id}}\left(\mathrm{mg} / \mathrm{g} \cdot \mathrm{min}^{0.5}\right)$ & 31.835 \\
\hline & $\mathrm{R}^{2}$ & 0.900 \\
\hline & SS & 726721 \\
\hline & MS & 72672 \\
\hline & $\mathrm{P}$ & $<0.0001$ \\
\hline
\end{tabular}




\subsection{Adsorption Isotherms}

In the adsorption processes, removal of the material from the solution continue until an equilibrium to be form between the adsorbent and adsorbate. The adsorption isotherm studies reveal the interaction between adsorbent and adsorbate when adsorption reaches equilibrium and show the maximum adsorption capacity of the adsorbent. In other words, the results of the isotherm studies are applied on the selection and to determine the potential efficiency of the adsorbent to be used before the results are put into practice in real scale. Process feasibility can be assessed for a given application by using experimental isotherms for example the most suitable adsorbent or the adsorbent dosage requirements can be determined. The regression coefficients of the four isotherm models used, and the parameters required to show the which isotherm is compatible are given in Table 2.

The correlation coefficients $\left(\mathrm{R}^{2}\right)$ for Freundlich and Langmuir models were found to be higher than the correlation coefficients of the other models. Both Freundlich and Langmuir models explained the isotherm behavior of adsorbent very well. Based on $\mathrm{R}^{2}$ values, Freundlich model $\left(\mathrm{R}^{2}: 0.9909\right)$ described the $\mathrm{Zn}(\mathrm{II})$ adsorption on HAp very well, implying that the adsorption process involved multi-molecular layers of coverage. Specifically, the $1 / \mathrm{n}$ value $(0.623)$ indicating that the adsorbent has relatively more homogeneous binding sites. However, the Langmuir model was found to be more consistent with the experimental results with correlation coefficient $R^{2}$ of 0.9978 . The separation factor $\left(R_{L}\right)$ was found to be between 0 and $1(0.227)$, and this value indicated to be a favorable sorption process for HAp. The Langmuir model shows that binding sites of adsorbent have an equal affinity for the adsorbate, and adsorption occurred with the formation of a monolayer by homogenous adsorbent sites. The results showed that $\mathrm{Zn}$ (II) ions perform monolayer coating on adsorbent surfaces and adsorption is homogeneous. The maximum $\mathrm{Zn}(\mathrm{II})$ adsorption capacities obtained by unit adsorbent mass were calculated from Langmuir model as $500 \mathrm{mg} / \mathrm{g}$.

Table 2. Isotherm parameters for $\mathrm{Zn}(\mathrm{II})$ adsorption on HAp

\begin{tabular}{|l|c|c|c|c|}
\hline Isotherms & \multicolumn{4}{|c|}{ Parameters } \\
\hline Langmuir & $\mathrm{R}^{2}$ & $\mathrm{~B}(\mathrm{~L} / \mathrm{mg})$ & $\mathrm{q}_{\mathrm{m}(\mathrm{mg} / \mathrm{g})}$ & $\mathrm{R}_{\mathrm{L}}$ \\
\cline { 2 - 5 } & 0.9993 & 0.136 & 500 & 0.227 \\
\hline \multirow{3}{*}{ Freundlich } & $\mathrm{R}^{2}$ & $\mathrm{~K}_{\mathrm{f}}(\mathrm{mg} / \mathrm{g})$ & $1 / \mathrm{n}$ & \\
\cline { 2 - 5 } & 0.9909 & 65.45 & 0.623 & \\
\hline \multirow{2}{*}{ Tempkin } & $\mathrm{R}^{2}$ & $\mathrm{~B}_{\mathrm{T}}$ & $\mathrm{A}_{\mathrm{T}}(\mathrm{L} / \mathrm{mg})$ & \\
\cline { 2 - 5 } & 0.9595 & 125.59 & 1.27 & \\
\hline \multirow{3}{*}{ Scatchard } & $\mathrm{R}^{2}$ & $\mathrm{~K}_{\mathrm{s}}$ & $\mathrm{Q}_{\mathrm{s}}$ & \\
\cline { 2 - 5 } & 0.9387 & 0.101 & 623.08 & \\
\hline Dubinin Radushkevich & $\mathrm{R}^{2}$ & $\mathrm{~B}$ & $\mathrm{Qs}$ & $\mathrm{E}$ \\
\cline { 2 - 6 } & 0.8479 & 2.979 & 331.98 & 2.44 \\
\hline
\end{tabular}




\section{CONCLUSIONS}

In this study, hydroxyapatite powders were prepared by wet co-precipitation method, and the batch adsorption experiments were performed to determine $\mathrm{Zn}(\mathrm{II})$ removal potential of them. Adsorption reactions were dependent on $\mathrm{pH}$, HAp amound, and contact time and initial $\mathrm{Zn}(\mathrm{II})$ concentration. After the adsorption reaction started, it happened rapidly and reached its maximum value in the first 45 minutes. While the optimum adsorbent concentration was 3.75 $\mathrm{g} / \mathrm{L}$, the adsorption efficiency was obtained as $90 \%$. Thus, HAp exhibited excellent adsorption performance for $\mathrm{Zn}(\mathrm{II})$ as a novel adsorbent with maximum adsorption capacity of $500 \mathrm{mg} / \mathrm{g}$. The kinetic behavior of HAp adapted to pseudo-second degree kinetic and pore diffusion models very well, and isotherm results could be explained by Langmuir and Freundlich isotherms. The results showed that hydroxyapatite particles obtained from natural sources or chemically synthesized can be a new alternative adsorbent for removing zinc ions from wastewater in treatment applications.

\section{REFERENCES}

[1] H.J. Fan, H.Y. Shu, H.S. Yang, W.C. Chen, Characteristics of landfill leachates in Central Taiwan, Sci. Total Environ. 361 (2006) 25-37.

[2] A.K. Bhattacharya, S.N. Mandal, S.K. Das, Adsorption of Zn(II) from aqueous solution by using different adsorbents, Chem. Eng. J. 123 (2006) 43-51.

[3] M.N. Rashed, Adsorption technique for the removal of organic pollutants from water and wastewater, INTECH Open Access Publisher, 2013 167-194.

[4] G. Crini, Non-conventional low-cost adsorbents for dye removal: a review, Bioresource Technol. 97 (2006)1061-1085.

[5] J.L. Gong, B. Wang, G.M. Zeng, C.P. Yang, C.G. Niu, Q.Y. Niu, W.J. Zhou, Y. Liang, Removal of cationic dyes from aqueous solution using magnetic multi-wall carbon nanotube nanocomposite as adsorbent, J. Hazard. Mater. 164 (2009)1517-1522.

[6] H. Çelebi, G. Gök, O. Gök, Adsorption capability of brewed tea waste in waters containing toxic lead(II), cadmium (II), nickel (II), and zinc(II) heavy metal ions, Scientific Reports 10, (2020) 17570.

[7] S. Ozcan, H. Celebi, Z. Ozcan, Removal of heavy metals from simulated water by using eggshell powder, Desalination and Water Treatment 127 (2018) 75-82.

[8] G. Liu, J. Gao, H. Ai, X. Chen, Applications and potential toxicity of magnetic iron oxide nanoparticles, Small 9 (2013) 1533-1545.

[9] S. Bao, L. Tang, K. Li, P. Ning, J. Peng, H. Guo, T. Zhu, Y. Liu, Highly selective removal of Zn(II) ion from hot-dip galvanizing pickling waste with amino-functionalized $\mathrm{Fe}_{3} \mathrm{O}_{4} @ \mathrm{SiO}_{2}$ magnetic nano-adsorbent, J. Colloid Interf. Sci. 462 (2016) 235-242. 
[10] H. Karami, Heavy metal removal from water by magnetite nanorods, Chem. Eng. J. 219 (2013) 209-216.

[11] M. Nagpal, R. Kakkar, Use of metal oxides for the adsorptive removal of toxic organic pollutants, Sep. Purif. Technol. 211 (2019) 522-539.

[12] J.I. Yoo, T. Shinagawa, J.P. Wood, W.P. Linak, D.A. Santoianni, C.J. King, J.O.L. Wendt, Hightemperature sorption of cesium and strontium on dispersed kaolinite powders, Environ. Sci. Technol. 39 (2005) 5087-5094.

[13] T. Wen, X. Wu, M. Liu, Z. Xing, X. Wang, A.W. Xu, Efficient capture of strontium from aqueous solutions using graphene oxide-hydroxyapatite nanocomposites, Dalton Trans. 43 (2014) 74647472 .

[14] D. Yang, S. Sarina, H. Zhu, H. Liu, Z. Zheng, M. Xie, S.V. Smith, S. Komarneni, Capture of radioactive cesium and iodide ions from water by using titanate nanofibers and nanotubes, Angew Chem. Int. Ed. Engl. 50 (2011) 10594-10598.

[15] N. Gupta, A.K. Kushwaha, M.C. Chattopadhyaya, Adsorptive removal of $\mathrm{Pb2+}$, $\mathrm{Co} 2+$ and $\mathrm{Ni2}+$ by hydroxyapatite/chitosan composite from aqueous solution, J. Taiwan Inst. Chem Eng 43(1) (2012) 125-131.

[16] I. Smiciklas, S. Dimovic, I. Plecas, M. Mitric, Removal of Co2 + from aqueous solutions by hydroxyapatite, Water Res. 40 (2006) 2267-2274.

[17] X. Xia, J. Shen, F. Cao, C. Wang, M. Tang, Q. Zhang, S. Wei, A facile synthesis of hydroxyapatite for effective removal strontium ion, J Hazard. Mater. 364 (2019) 326-335.

[18] S. Sugiyama, T. Ichii, F. Masayoshi, K. Kawashiro, T. Tomida, N. Shigemoto, H. Hayashi, Heavy metal immobilization in aqueous solution using calcium phosphate and calcium hydrogen phosphates, J Colloid Interface Sci. 259 (2003) 408-410.

[19] Y. Wang, Y. Liu, H. Lu, R. Yang, S. Yang, Competitive adsorption of Pb(II), Cu(II), and Zn(II) ions ontohydroxyapatite-biochar nanocomposite in aqueous solutions, J Solid State Chem. 261 (2018) 53-61.

[20] S. Lagergren, About the theory of so-called adsorption of soluble substances, Kungliga Svenska Vetenskapsakademiens, Handlingar, Band 24, 1898, 1-39.

[21] Y.S. Ho, G. Mckay, Pseudo-second order model for sorption processes, Process Biochem. 34 (1999) $451-465$.

[22] W.J. Jr Weber, J.C. Morriss, Kinetics of adsorption on carbon from solution, J. Sanit. Eng. Div. 89 (1963) 31-60.

[23] K.R. Hall, L.C. Eagleton, A. Acrivos, T. Vermeulen, Pore and solid diffusion kinetics in fixed-bed adsorption under constant- pattern conditions, Ind. Eng. Chem. Fundam., 5 (1966) 212-223.

[24] T. Jiun-Horng, C. Hsiu-Mei, H. Guan-Yinag, C. Hung-Lung, Adsorption characteristics of acetone, chloroform and acetonitrile on sludge-derived adsorbent, commercial granular activated carbon and activated carbon fibers, J Hazard Mater. 154 (2008) 1183-1191.

[25] M. Ghasemi, S. Mashhadi, M. Asif, I. Tyagi, S. Agarwal, V.K. Gupta, Microwave-assisted synthesis of tetraethylenepentamine functionalized activated carbon with high adsorption capacity for Malachite green dye, J. Mol. Liq. 213 (2016) 317-325. 
[26] S. Mashhadi, R. Sohrabi, H. Javadian, M. Ghasemi, I. Tyagi, S. Agarwal, V.K. Gupta, Rapid removal of $\mathrm{Hg}$ (II) from aqueous solution by rice straw activated carbon prepared by microwave assisted $\mathrm{H}_{2} \mathrm{SO}_{4}$ activation: kinetic, isotherm and thermodynamic studies, J. Mol. Liq. 215 (2016) 144-153.

[27] C. Qi, Q.L. Tang, Y.J. Zhu, X.Y. Zhao, F. Chen, Microwave-assisted hydrothermal rapid synthesis of hydroxyapatite nanowires using adenosine 5'-triphosphate disodium salt as phosphorus source, Materials Letters, 85 (2012) 71-73.

[28] G.N. Kousalya, R.M. Gandhi, C. Sairam Sundaran, S. Meenakshi, Synthesis of nanohydroxyapatite chitin/chitosan hybrid biocomposites for the removal of $\mathrm{Fe}(\mathrm{III})$, Carbohydr. Polym. 82 (2010) 594-599.

[29] Y. Li, S. Wang, Y. Zhang, R. Han, W. Wei, Enhanced tetracycline adsorption onto hydroxyapatite by $\mathrm{Fe}$ (III) incorporation, J. Mol. Liq. 247 (2017) 171-181.

[30] W. Yaoguang, H. Lihua, Z. Guangya, Y. Tao, Y. Liangguo, W. Qin, D. Bin, Removal of Pb(II) and methylene blue from aqueous solution by magnetic hydroxyapatite-immobilized oxidized multiwalled carbon nanotubes, J. Colloid Interface Sci. 494 (2017) 380-388.

[31] A. Vahdat, B. Ghasemi, M. Yousefpour, Synthesis of hydroxyapatite and hydroxyapatite/Fe3O4 nanocomposite for removal of heavy metals, Environ. Nanotechnol. Monit. Manage 12 (2019) 100233.

[32] D.N. Thanh, M. Singh, P. Ulbrich, F. Štěpánek, N. Strnadová, As $(V)$ removal from aqueous media using $\alpha$-MnO2 nanorods-impregnated laterite composite adsorbents, Mater. Res. Bull. 47 (2012) $42-50$.

[33] G. Nahid, G. Maryam, M. Saleh, G. Paris, S.A. Njud, K.G. Vinod, S. Agarwal, I.V. Burakova, AV Tkachev, Zn (II) removal by amino-functionalized magnetic nanoparticles: kinetics, isotherm, and thermodynamic aspects of adsorption, J. Ind. Eng. Chem. 62 (2018) 302-310.

[34] M.G. Saida, N. Frini-Srasra, A comparison of single and mixed pillared clays for zinc and chromium cations removal, Appl. Clay. Sci. 158 (2018) 150-157.

[35] S. Chayan, K. Jayanta, A. Basu, S. Nath, Synthesis of mesoporous geopolymeric powder from LD slag as superior adsorbent for zinc (II) removal, Adv. Powder Technol. 29 (2018) 1142-1152.

[36] S.B. Kanungo, S.S. Tripathy, Rajeev, Adsorption of $\mathrm{Co}, \mathrm{Ni}, \mathrm{Cu}$, and $\mathrm{Zn}$ on hydrous manganese dioxide from complex electrolyte solutions resembling sea water in major ion content, J. Colloid Interface Sci. 269 (2004) 1-10.

[37] E. Valsami-Jones, K.V. Ragnarsdottir, A. Putnis, D. Bosbach, A.J. Kemp, G. Cressey, The dissolution of apatite in the presence of aqueous metal cations at pH 2-7, Chem. Geol. 151 (1998) 215-233.

[38] M. Harja, G. Ciobanu, Studies on adsorption of oxytetracycline from aqueous solutions onto hydroxyapatite, Sci. Total Environ. 628-629 (2018) 36-43.

[39] S. Periyasamy, V. Gopalakannan, N. Viswanathan, Hydrothermal assisted magnetic nanohydroxyapatite encapsulated alginate beads for efficient $\mathrm{Cr}(\mathrm{VI})$ uptake from water, J. Environ. Chem. Eng. 6 (2018) 1443-1454. 